\title{
Ethical perspectives on the environmental impact of property development
}

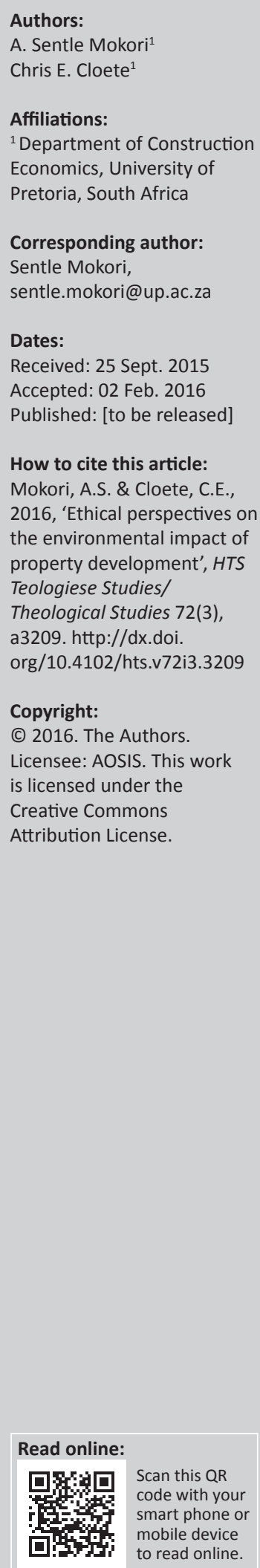

Three perspectives that can be found in ethical decision-making are explored to suggest guidelines for ethical property development: the instrumental, the intrinsic and the pluralist perspective. Given the limitations of the instrumental and the intrinsic perspectives, it is suggested that the appropriate perspective to be adopted by ethical property developers is that of pragmatism, as being a system of moral pluralism. This perspective can be utilised as a flexible toolbox which unites both traditional ethical values and the diversity of environmental ethics, as well as allowing new values to emerge without adhering to relativism.

\section{Introduction}

Feasibility studies in property development have mainly focused on economic aspects, and more recently on environmental and socio-economic aspects (see Cloete 2006, 2008, 2016a, 2016b). However, the investigation of the ethical perspectives on the environmental impact of property development remains a gap to be filled in property studies. It is therefore the purpose of this study to fill this gap by investigating the following research questions.

What perspectives on environmental concerns exist in philosophical literature? Do these perspectives have implications for ethical property development? What are these implications? These questions have become very relevant for property developers concerned with the broader impact of their actions on the physical and socio-economic environment. This study explores the ethical perspectives that can be found in ethical decision-making to suggest a particular course of action in relation to environmental concerns in property development.

Three perspectives can be distinguished in philosophical literature regarding environmental concerns. These are:

- The instrumental perspective - this is represented by traditional ethical theories (see VanDeVeer \& Pierce 2003);

- The intrinsic perspective - this is dominated by a diversity of environmental ethics (see Callicott 1984; Hargrove 1989); and

- The pluralist perspective - environmental pragmatism (which has been proposed as a new line of attack in environmental ethics literature) serves as an example (see Hattingh 2011; Light 1996b; Norton 2003; Weston 1996).

Some implications for ethical property development guided by these perspectives will be explored. The above aims can be reached through a critical literature review of relevant theoretical and philosophical writings based on these perspectives, without being conclusive about the topic in discussion.

\section{Instrumental perspectives}

The notion of an instrumental perspective can be described as a view on the value or usefulness of a particular asset or service in terms of its exchange value for something else. An example would be that if one has a thousand rand to spend, the thousand rand can be valued as instrumental when it is exchanged for another value (like buying a product). Three dominant ethical theories to ethical decision-making, namely the rights approach, the consequentialist approach and the virtue approach serve as examples of this perspective.

\section{The rights approach}

This approach regulates the difference between having a right and having a duty. 
To illustrate this point, consider the Gautrain project in South Africa. Every South African might have the moral right to use it, but this does not imply that everyone has a duty (or has the means to afford) to use it. Alternatively, consider the equation 'A has a right against B to do $X$ ' (VanDeVeer \& Pierce 2003:20). Applied to the Gautrain example, this means that everyone who can afford to use the Gautrain is allowed to or has a right to use it. This would then imply that those who cannot afford the luxury of using the Gautrain, have no right to prevent those who can afford to use from enjoying the privileges of using it. In other words, they have the duty (moral responsibility) to respect the right of others. Since the Gautrain seems to only exist as a right to those who can afford it, the question remains whether everyone should not have similar rights. This leads to a plurality of rights. VanDeVeer and Pierce (2003:21) highlight that '[m]any rights are often, arguably, packages of rights'. Consider the notion of property rights. Having (or owning) a property entails having a property right. This raises the question: Would those who own property have the right to use it as they please? More specifically:

Do those with legal property rights to a wetland have a moral right to destroy it - even when to do so would be to wreak serious ecological damage to the surrounding ecosystem and eventually permanent losses to the chain of future generations? (VanDeVeer \& Pierce 2003:21)

This points towards a related question raised by Stone's book (1972) titled: Should trees have standing? That is what value or rights do non-human organisms hold?

In response to this question, Kant (1963) developed deontological ethics. This is an ethical theory that focuses on act-duty relations. When it comes to determining the rights of non-human animals, Kant's ethics (based upon two corresponding versions of the deontological ethics) does not extend human duty and responsibility towards animals. These are:

- The first version reads that a moral agent, human being as a rational being - ought to act in terms of a principle that determines their action to become a universal guideline that every moral agent can act upon. Deontological ethics, therefore, suggests that whatsoever is right, good and a duty to one moral agent should likewise be to other moral agents. In this regard it is advisable for a rational agent to help other agents, not only when it is expedient, but because in a similar circumstance they might be in need of similar help.

- The second version of deontological ethics articulates that a moral agent should never be treated as a mere means for further ends (see Kant 1963:239).

With the deontological approach, a possible response to whether those moral agents with legal property rights to a wetland have a moral right to extinguish it, would be that human beings are moral agents, they are rational beings and therefore have rights and a direct duty towards each other. This would imply that their moral duties do not apply to non-human animals because animals do not possess rationality like humans. In this regard, non-human animals do not possess rights. Therefore: 'Everyone who owns property has the duty, of course, to exercise his or her property rights in ways that respect the similar rights of [other human beings]' (Sagoff 2003:378). Even when exercising such duty would cause destruction to non-human animals to the point of losing the chain of future generations, human rights are given a higher priority. Kant explicitly argues that:

... so far as animals are concerned, we [as human beings] have no direct duty. Animals are not self-conscious and are there merely as a means to an end. That end is man. (Kant 1963:239)

Most conversations about rights, as noted, become more individualistic and self-regarding because the notion of rights is often attributed to individual moral agents.

In addition, Kant's deontological ethics principle has been subject to critical scrutiny by Bentham (1789) and his follower Mill (1861) - the most celebrated exponents of consequential utilitarianism. VanDeVeer and Pierce (2003:23) write: 'It was, in fact, the view of Bentham ... that we have only certain duties and that talk about rights (moral, not legal) is "nonsense on stilts"'. To understand the ground of this critique, a consequentialist, utilitarian approach should be presented.

\section{Consequentialist approach: utilitarian}

This can be considered as an opposite of the preceding approach. As the rights approach (such as Kant's deontological ethics principle) upholds, morality is built on human reason, duties and actions, as well as rights. On the contrary, the consequentialist utilitarian approach advocates that a moral value of a particular course of action is determined by the consequence that results from such an action (Woermann 2010:32). A right or good action should be one that provides the highest good to the majority of human beings as moral agents.

Utilitarianism as a consequentialist approach is commonly expressed through the principle: 'the greatest happiness of the greatest number' (Burns 2005:46). This implies that utilitarianism attempts to reduce pain and increase pleasure for most people and some sentient animals. As Bentham puts it:

Nature has placed mankind under the governance of two sovereign masters, pain and pleasure. It is for them alone to point out what we ought to do, as well as to determine what we shall do. (Bentham 1789:42)

This presupposes the principle of utility. This principle, on the one hand, attempts to maximise certain benefits, advantages, pleasure, good, as well as happiness, as outcomes of a particular course of action. On the other hand, however, it inclines to minimise or prevent things like harm, pain, evil and misery to the greater number of moral agents (Bentham 1879). 
Moreover, the consequentialist utilitarian approach can be related with the most controversial decision-making technique, that is the cost-benefit analysis. (This technique shall briefly be elaborated upon later in this study.)

\section{Virtue approach}

Instead of focusing on the consequences of an action (utilitarianism) and on duties or rules (deontological ethics), the virtue approach deliberates on some virtues that can allow a human being to behave and thus act in a way that complements the highest possible human character. Consider this: if a particular moral agent needs assistance about a particular issue, an ethicist, as discussed above, acting from a deontological point of view would act in accordance with a certain moral rule or duty. A consequentialist would act in terms of the consequences of action. But an ethicist acting according to the virtue approach would be assisting such a person because it would be generous and benevolent to do so. In other words, the cultivation of virtue - such as goodness, respect and integrity - can contribute to human responsibility and character (see Woermann 2010). The basic question of the virtue approach would be: 'what kind of a person should one become?' To answer this question, the goodness and wrongness of a particular action can be established only when a certain virtue or vice is adequately conveyed. In short, morality is about the cultivation of the human character. A leading proponent of this approach is Aristotle. Like Kant, Aristotle emphasises the notion of rationality and the chain of command of nature (Pearce 2009:10). Aristotle $(1988: 1,2)$ states that: ‘[p]lants exit ... for the sake of animals ... All other animals exist for the sake of man'. As they possess the capability to reason above nonhuman animals, humans have special status in creation. Since this approach is located on human character, it is therefore inevitably anthropocentric. In virtue theory, similar to the rights approach and the consequentialist utilitarian approach, non-human animals can only be esteemed in terms of instrumental value.

\section{Intrinsic perspectives}

This position is a response and contrast to the previous position. A value can be perceived as intrinsic if it has a particular value independent from something else. A human life and some of the sentient non-human animals can be considered to have intrinsic value because it is good to be alive - not because it would lead to something different outside being alive; living is valuable and therefore good.

In light of this, a call was finally made for a new ethical consideration setting out the relationship between human beings and the non-human world (see Routley 1973), enquiring whether there can be a non-anthropocentric, intrinsic perspective that is not grounded merely on human interest. Environmental ethics was at last established as an autonomous field of study. The moral dominance of humans over other species was interrogated and the rational possibility of assigning intrinsic value to the entire community of life was explored (see Attfield 1991; Callicott 1984; Hargrove 1989). The environmental ethics discipline can be seen as the process of increasing the diversity of theoretical values (Hattingh 2011:71). These include animal rights and liberations values, eco-centrism and biocentrism, radical approaches (the politics of the transformation movement), as well as deep ecology.

\section{Animal rights and liberations values}

Animal rights and liberations - as advocated by prominent philosophers and activists such as Singer (1975) and Regan (1983) - suggest that the boundaries of human's moral considerations should be extended to certain animals. Singer (1975) borrows the notion 'speciesism' from Richard D. Ryder to contend against any form of discrimination against members of other species. Speciesism is 'a prejudice or attitude of bias in favour of the interests of members of one's own species and against those of members of other species' (Singer 1995:120).

Singer claims that the interests of all organisms that are capable of suffering should be taken into consideration. This idea is based on a utilitarian notion, specifically, the equality formula by Bentham who observes that '[e]ach to count for one and none for more than one' (Singer 1995:36). This means that the well-being of each entity that has interests should be deliberated and preserved in the same way as the interests of human beings. Along with his rejection of animal vivisection, Singer suggests that human beings should become vegetarian as a practical way forward to lessen this problem of suffering.

Based on this train of thought, Regan (2004) argues that certain animals have moral rights, from a Kantian deontological perspective. This position is based on the fact that being a 'subject-of-a-life' is necessary for having inherent worth, regardless of whether this worth is recognised or not (Regan 2004:243). Although they use different approaches, such as utilitarianism or deontology, Singer and Regan can be perceived as holding similar viewpoints - both are deeply concerned about the well-being of animals.

\section{Eco-centrism and biocentrism}

In contrast to instrumentalism, which maintains that only human beings are worthy of moral concerns, two approaches focusing on the intrinsic value of the biosphere-eco-centrism and biocentrism - have been formulated.

On the one hand, eco-centrists try to extend moral consideration to encompass all non-human animals. This approach is advocated by, among others, thinkers such as Callicott (1990), Leopold (1949 [1970]) and Taylor (1981). Leopold (1949 [1970]:213) pointed out that 'conservation is a state of harmony between man and land'. The notion of land ethic broadens the borders of moral obligations towards the land, which includes animals, plants, water and many other non-human organisms. In a nutshell, the land ethic inspires human beings to consider making a transition from being 
exploiters of the biotic community to becoming simple citizens of this community, together with all non-human organisms.

Leopold's idea of land ethic was further developed and defended by Callicott (1984). He attempts to present both a defence and an intellectual foundation of Leopold's ideas about the land ethic in order to make his views more comprehensive (see Callicott 1984, 1990. During his search for a universal, monistic moral principle, Callicott (1985) began by pointing out that the most important challenge facing environmental ethicists is constructing a workable and suitable non-anthropocentric value theory for non-human animals and nature as a whole. The major problem with this is that there is a difference between subject and object as in the sense of Descartes. Callicott (1985:270) adopted certain quantum theory ideas to construct his understanding of the non-anthropocentric, inherent value of nature. Like the ideas of many other prominent scholars, Callicott's views were also critiqued. With regard to his position on Leopold's land ethic, Regan (1983) charged Callicott with ecofascism. The notion of ecofascism, according to Zimmerman can be described as:
... a totalitarian government that requires individuals to sacrifice their interests to the well-being and glory of the 'land', understood as the splendid web of life, or the organic whole of nature, including peoples and their states. (Zimmerman 2005:531-532)

This criticism was raised because Leopold suggested the following: for the preservation of the beauty and the stability of the biotic community, especially when a certain region becomes heavily populated by members of a particular species - deer for example, it could be suggested that such members should be harvested. This is not obligatory in human terms and the problem is, therefore, that the view lacks consistency when it comes to the human population.

On the other hand, bio-centrists, such as Lanza (2007), argue that every scientific model that tries to understand the physical universe should begin with human consciousness, instead of the hypothesis that the universe produces life. Today it seems outrageous to hope that someday thinkers will succeed in proposing a universal theory that can resolve every problem. Biocentrism upholds the view that, for other scientific disciplines to succeed in coming up with a universal principle that can govern almost everything, they should start with biology. Taylor (1981:197) thus offered an introductory outline for 'a life-centered theory of environmental ethics': the structure which consists of three interrelated components. These are:

- As an ultimate moral position, biocentrism encourages respect for nature.

- It also promotes a conviction which motivates a suitable attitude towards the natural environment and the communities of life.

- Furthermore, it makes provision for a system of moral standards that can guide human behaviour towards nature, and also encourages sets of principles which can provide a solid picture of respect for nature.

The major aim of Taylor's contribution (1981:218) was 'to try to establish a base point from which we can start working toward a solution to the problem'. In order to achieve this, he suggests respecting the interests of non-human organisms, controlling population growth and also being willing to share the Earth's abundance with members of other species. Taylor (1981:218) states that humans as moral beings should display moral commitment by respecting nature.

In summary, from the perspective of the instrumental value theory, the moral consideration is merely preserved for humans, and nature is only cherished for its instrumental use. However, this position is challenged and opposed by the elected ethicists who extended the moral obligation to all non-human organisms. This contrast summarises the fundamental disputes within environmental ethics, that is, the instrumental-intrinsic value argument.

\section{Radical approaches or the politics of the transformation movement}

Radical positions are often treated as independent value theories, but they fall under the intrinsic value category. The environmental ethics of the radical movements emerged during the 1980s and their focus was on the root causes of ecological concerns. Hattingh (2011:70) says that the main argument of this movement is that environmental ethics and mainstream environmentalism offer an artificial reflection of the roots and the structure of the existing ecological crisis. In other words, this movement argues that the way in which both environmental ethics and mainstream environmentalism respond towards the ecological crisis is entirely inappropriate. This position is a distinct movement which incorporates different values such as deep ecology, ecofeminism and social ecology. This article will pay special attention to only one of the values, that is, deep ecology.

\section{Deep ecology}

Deep ecology is a radical movement that collaborates with some of the non-anthropocentric approaches - like ecocentrism and biocentrism - against anthropocentric attitudes towards nature. It argues that the Western egocentric and individualistic perception of self-realisation poses a real danger to the natural environment. The anthropocentric attitude towards the environment is associated with social atomism, capitalist materialism and over-consumption in the modern world (Hattingh 2011:78). Anthropocentrism, in other words, is a danger which should be overcome first before we can start hoping to solve current environmental problems (Naess 1984). Deep ecology promotes a deep spiritual connection with nature because entities in the universe are fundamentally connected with each other. In short, things are valuable as fragments of the whole scope of nature. The inherent value of nature can be revealed and 
recognised through the identification approach. As Hattingh pointed out:

In practical terms, this entails an intuitive experience of the harmony and wholeness of nature. This intuitive and immediate identification with nature, inspired by phenomenology, Vedantic Hinduism, the science of ecology and the philosophy of Spinoza, moves us beyond class, gender and species divisions in order to be in full harmony with nature. (Hattingh 2011:78)

This leads us to the practical ideas of deep ecology which have been conveyed in terms of Naess's proposals of ecological philosophy (1984). Both human beings and nonhuman organisms have intrinsic value. Environmental policies and conversations - with regard to science, technology, politics and ethical conducts around the world should be transformed in such a way that the intrinsic value of the whole biotic community is respected. This would then imply that the higher standard of living of humans should be reduced all organisms are valued equally (Naess 1984).

Naess puts emphasis on the intrinsic values of biodiversity, reduction of the human population, and a radical change of attitude towards human consumption customs. Deep ecologists strongly argue that other means of survival should be explored rather than continuing to live in the conventional way that is characterised by blind anthropocentrism.

In conclusion, the deep-seated objective of intrinsic perspectives was to come up with a single value theory that is universal enough to support the practical mission of resolving the ecological crisis and thus sustain life on earth. However, environmental ethics as a field of study has failed to come up with such a value theory and it is also not certain that it can be constructed at least in the near future.

In what follows, the paradigm of pragmatism which was introduced above serves as an example of ethical pluralism which is required in order for environmental ethics to move forward.

\section{Pluralist perspective}

Environmental pragmatism is a pluralist paradigm. It attempts to conserve the environment by incorporating some ideas developed by classical pragmatists (e.g. Charles Sanders Peirce; William James and John Dewey) within environmental ethics.

These pragmatists find inspiration from the philosophical tradition which originated in America around 1870. Although there are some differences in their individual interpretation of the concept, the underlying idea within pragmatism can be summed up in the pragmatist maxim that a hypothesis can be clarified by tracing its practical outcomes. In other words, this axiom takes the following principles into consideration: the usefulness of a theory should be based on its practical implication; the practicality of an idea should be guided by an action; and the perception of truth should be verified by practical conviction. The classical pragmatists, therefore, offered a comprehensive paradigm, but did not anticipate the environmental problems experienced today. Parker observes the same principle when he says:

When it comes to applying these insights [classical pragmatist ideas] to contemporary issues of 'the environment', and to developing the details of legitimate environmental philosophy, we enter new territory. (Parker 1996:28)

The promise of environmental pragmatism is that it can assist decision-makers and practitioners to integrate different values in order to enable them to reform institutions and practices. When standing values evolve into practice, that is policy discussion platforms, new perspectives and stronger values can emerge. In this regard, environmental pragmatism does not commence with theory but with practice. This is because, by merely focusing on theoretical arguments and debates, progress in environmental policy discussion can be obstructed (see Light 1996a, 1996b).

With the pragmatic turn, the split between ethical theories and environmental values, as well as between theories and practices can no longer be emphasised, because these previous antagonists are now perceived to be in need of each other. As a huge number of different values are now coming together, the framework of ethical decision-making can, therefore, be viewed as a large toolbox which is available when making ethical decisions (Hattingh 2011:80). This toolbox, according to Weston (1985, 1996, serves as an ecology of values: a multiplicity of ideas. These ideas are available whenever needed and '[t]hrough engagement with practical problems, we can also shape new tools [as values] for this kit, adding to it or refining it as we go along' (Hattingh 2011:80). This is because the ecology of values as a network of ideas allows interaction between diversity of values. As Weston (1985:322) pointed out, '[v]alues so conceived are resilient under stress, because, when put to question, a value can draw upon those other values, beliefs, etc. which hold it in place in the larger system'. This approach is consistent with a participative approach to decision-making (Cloete 2016b).

This means that, even though values influence each other reciprocally in decision-making conversations, most values are exposed to criticisms and transformation because they are different (Weston 1996:286). In spite of this, pragmatism provides a practical, supportive framework where the diversity of values can co-exist and where new, robust and concrete values can emerge and flourish.

Furthermore, pragmatism offers Norton's adaptive management principle which entails a multi-scalar analysis on the basis of time and location, as well as tolerance. Tolerance is essential when it comes to avoiding incompatible disagreements between overlapping theorists in policy decision-making. A multi-scalar evaluation, according to Norton (2005:93), puts emphasis on the importance of conceptualising environmental concerns and values within the multiple frameworks of time and space. 
To illustrate this, Norton (2005) makes a distinction between time scales.

- The first scale is from 0 to 5 years. This is a time scale where various profitable decision-making processes take place. For example, this is where human values, as tools, are given the highest priority to estimate the natural environment.

- The second time scale starts from 5 to 200 years. This represents the assessment of the transition from the individual towards the community. It is through a considerable time scale where interaction between values has effect.

- The third time scale represents an open-ended process. This presupposes the survival of the community of life on earth. As human actions keep on polluting the environment without restrictions, such as when humans burn fossil fuels which trigger an escalation of greenhouse gases in the atmosphere, the ecological system will be influenced negatively. As noted, the community of life will remain threatened until there is a change of direction. This multi-scalar analysis focuses on the concept of time.

Now, it is vital to reflect on the multi-scalar analysis in terms of locality. In order for different species to adapt to certain conditions, they require certain locations. In other words, the survival of particular species is entirely determined by particular locations. This also applies to a diversity of values. Values are contextual. They can transform practices once they are situated within a particular locality within a framework of time. Values are therefore temporal, provisional and conditional (Norton 2005:93).

In this light it is, therefore, suggested that ethical decisionmaking should incorporate the diversity of values, for example the utilitarian approach, the rights approach or the eco-centric approach when considering a possible course of action. It should, over a long scale of time, take environmental as well as social concerns into consideration. The notion of truth is an open-ended development which surfaces within a certain frame of time and place. It can always be revised and modified. To this end, the diversity of values is not a problem to be resolved but rather should be seen as a resource by which the claim for truth can be operational in transforming short-term practice into long-term scales.

\section{Implications for (ethical) property development}

This section explores the implications of ethical property development guided by the three ethical perspectives discussed above. Before doing this, it is important to first provide an interested reader with a brief overview of the property development paradigm.

\section{A brief overview}

Property development can be defined to be '... the process directed at the increase in value of an existing property (undervalued or developed) by the application of resources (material human and capital)' (Cloete 2016a:3). It can therefore be understood as a dynamic system which is concerned, for example, with the production of physical and social space in the form of commercial and domestic buildings. Depending on the nature of the property development project, the viability of a property development is commonly measured in terms of an economic feasibility study. This is a valuable tool to determine the possible successes and returns of a particular property development or investment (Cloete 2006). The cost-benefit analysis is one example. It is the most effective and extensively used economic metric for investment assessments. Even though the cost-benefit analysis can be useful to determine the success of a certain property development in monetary terms, the predicament is that it is subject to a number of constraints, such as determining the intrinsic value of non-human organisms (Cloete 2006). Here the non-human organisms among other factors are characterised '... as an "externality" ... that can be included as a factor in the price of producing goods and services' (Seeliger 2009:ii). In other words, the inherent value of non-human organisms can merely be measured in terms of an exchange value. For this reason, the intrinsic value of some of the non-human organisms has been ignored.

\section{Implications}

In light of this overview, what is missing within the discipline of property development is the inability of developers to take due cognisance of the ethical perspectives that moral philosophy provides. These ethical perspectives can be summarised as follows.

- The traditional ethical theories, namely utilitarianism, rights approach and virtue theory are limited to instrumentalism, since they cannot extend the intrinsic value towards non-human organisms. However, the implication of the consequentialist utilitarian approach for ethical property development is that it utilises the principle of utility. This principle can be associated with the cost-benefit analysis that traditionally has been used in property development. The purpose of the principle of utility is to minimise costs (loss) by maximising benefit (income) to the greatest number of human beings. As Cloete (2016b:1) states, '... when the feasibility of a proposed property development is being considered, benefits are compared with costs, where benefits are defined as increases in human well-being (utility) and costs are defined as reductions in human well-being'. The implication of the rights approach for property development is that it proposes the principle of rationality. The principle of rationality is important because it pays attention to who has rights, freedom and liberty and also determines that such rights, freedom and liberty are respected. When, for example, the Kariba Dam was built in Zimbabwe, it changed the ecology of the Kariba Valley, caused extensive displacement of animals (rescued by 'Operation Noah') and also the flooding of human settlements that had been present in the valley. The rights and freedom of certain groups of humans were sacrificed 
for the potential benefits to other citizens. Similar examples abound. The implication of the virtue approach (unlike in both utilitarianism and the rights approach) is that the moral character of a moral agent, a human being, is taken into consideration, since morality is determined by way of the cultivating of the human character. However, a problematic implication of the traditional ethical theories is that these theories may offer only a onesided approach to ethical property development, because the notion of intrinsic value is not extended to non-human organisms, but it is confined to humans. Whether ethical values should be extended to non-human organisms, or should be confined to, for example, sentient organisms only, is of course a moot point.

- Given the one-sidedness as well as some limitations to the traditional ethical perspectives it is inevitable that the field of environmental ethics embodies a diversity of environmental values. These include animal rights and liberations values, eco-centrism and biocentrism, radical approaches and the politics of the transformation movement, as well as deep ecology. The implications that these ethical perspectives hold for ethical property development are that many of them strongly argue for the intrinsic value of the entire community of life, both human beings and non-human organisms, in contrast to the traditional ethical theories. For example, the proponents of animal rights and liberations, unlike proponents of the rights approach and utilitarianism, maintain that the boundaries of human moral concerns should be stretched towards some non-human animals. Bio-centrists like Taylor (1981:218) uphold that as moral agents, human beings should respect the natural environment as it also has intrinsic value. Eco-centrists maintain that environmental preservation is the basis of a harmonious relationship between the land and human beings (Leopold 1949 [1970]). Deep ecology thus integrates most of the non-anthropocentric environmental values. However, there are also problematic implications concerning a diversity of values in environmental ethics. Unlike traditional ethical perspectives, these values do not offer clear guidelines determining a particular course of action. Many of these values from a theoretical perspective overlap, even though there are some differences amongst them, because of disagreements and disputes prevalent amongst environmental philosophers.

- The implication of the pragmatic approach is that it takes a concrete practical context as a point of departure for ethical property development. In other words, it tries to avoid monistic and reductionist strategies. The most important aspect of this approach is that both traditional theories and a diversity of environmental values can be incorporated under a single umbrella (or a large toolkit) without reducing them to a single theory like moral monism. Different vantage points and robust values can develop, especially, when existing values evolve and mingle with each other within practice that is policy discussion context. In this regard, traditional ethical theories and a diversity of environmental values and the distinction between intrinsic and instrumental dichotomy can be reconciled. In addition, the other implication is that the pragmatic approach proposes Norton's strategies of experimentalism, multi-scalar exploration and localism for the implementation of the property development decisionmaking process. These are flexible, experimental, and pluralistic, as well as interactive strategies which can support the decision-makers to make useful decisions about environmental values in property policymaking. The pragmatic approach as experimentalism is committed to a continuous engagement with human experience in order to reduce some uncertainty about property development and environmental values. These experiments encompass a number of indecisions because the outcomes remain open-ended. Thus, a cautious experimentation based on experience should be used in order to decide on workable decisions, or a participative approach to decision-making may be implemented (Cloete 2016b). This can also assist the property development decision-makers to modify their objectives and prospects about the nature of development in order to accommodate environmental values when deciding about a particular investment. When it comes to incompatible disputes between overlapping values in ethical decision-making procedures, the pragmatic approach provides a principle of tolerance to avoid such disputes. For example, the proximity of a mining development to an ecologically sensitive area like the Mapungubwe World Heritage Site may be restricted.

\section{Conclusion}

Given the aim of this study, which was to explore the ethical perspectives that can be established in philosophical literature for ethical decision-making in relation to environmental problems, three perspectives (i.e., the instrumental, intrinsic and pluralist perspectives) were distinguished and their implications for ethical property development explored.

The problem with both the instrumental position of the traditional ethical values and the diversity of intrinsic values in environmental ethics is that they are one-dimensional. It was shown that the traditional ethical values merely articulate the value of non-human organisms with regard to instrumental value.

In contrast to these views, the overall implication of pragmatism, as a system of moral pluralism, is that it can be utilised as a flexible toolbox which unites both traditional ethical values and the diversity of environmental ethics, as well as allowing new values to emerge without adhering to relativism. As it challenges the parameters of conventional feasibility studies of property development, pragmatism also functions as a suitable basis towards ethical policies in property development. Pragmatism allows a participative approach to decision-making, which may provide a basis on which common ground may emerge. 


\section{Acknowledgements Competing interests}

The authors declare that they have no financial or personal relationships which may have inappropriately influenced them in writing this article.

\section{Authors' contributions}

This research was part of research for an MSc degree in Real Estate in the Department Construction Economics, Faculty of EBIT, University of Pretoria, by A.S.M under the supervision of C.E.C. C.E.C. provided research direction and conceptualisation. A.S.M. compiled the research and did conceptual contributions, as well as the execution of this study.

\section{References}

Aristotle, 1988, Politics, Cambridge University Press, Cambridge.

Attfield, R., 1991, The ethics of environmental concern, University of Georgia Press, Athens, GA.

Bentham, J., 1879, An introduction to the principles of morals and legislation Clarendon Press, Clarendon

Bentham, J., 1789, The principles of moral and legislation, Oxford University Press, Cambridge.

Burns, J.H., 2005, 'Happiness and utility: Jeremy Bentham's equation', Utilitas 17(1) 46-61. http://dx.doi.org/10.1017/S0953820804001396

Callicott, J.B., 1984, 'Non-anthropocentric value theory and environmental ethics', American Philosophical Quarterly 21(3), 299-309.

Callicott, J.B., 1985, 'Intrinsic value, quantum theory, and environmental ethics' Environmental Ethics 7(3), 257-275. http://dx.doi.org/10.5840/enviroethics 19857334

Callicott, J.B., 1990, 'The case against moral pluralism', Environmental Ethics 12(2) 99-124. http://dx.doi.org/10.5840/enviroethics199012220

Cloete, C.E., 2006, Feasibility studies. Principles and practice, South African Property Education Trust, Sandton.

Cloete, C.E., 2008, 'Viability studies: Methodological constraints', paper presented at the RICS Construction, Building and Real Estate Research (COBRA) conference, Dublin Institute of Technology, Dublin, Ireland, 4-5 September.

Cloete, C.E., 2016a, Property development, South African Property Education Trust, Sandton.

Cloete, C.E., 2016b, 'How should we deal with socio-economic values in development decisions?', in Ruben Paul Borg, Paul Gauci and Cyril Spiteri Staines (eds.), Europe and the Mediterranean: Towards a Sustainable Built Environment, Proceedings of the SBE16 Malta International Conference, Valetta, Malta, 16-18 March 2016 239-245, SBE-Malta, Sustainable Built Environment.

Hargrove, E., 1989, Foundations of environmental ethics, Prentice Hall, Englewood Cliffs, NJ.
Hattingh, J.P., 2011, 'Towards a shared ethics of global climate change: Ethics', Current Allergy \& Clinical Immunology 24(2), 91-96.

Kant, I., 1963, 'Duties towards animals and spirits', Lectures on Ethics 239, 239-241.

Lanza, R., 2007, 'A new theory of the universe', American Scholar 76(2), 18.

Leopold, A., 1949 [1970], 'The land ethic', in Aldo Leopold (ed.), A Sand County Almanac, pp. 201-214, Ballantine, New York.

Light, A., 1996a, 'Compatibilism in political ecology', in A. Light \& E. Katz (eds.), Environmental pragmatism, pp. 161-184, Routledge Press, New York.

Light, A., 1996b, 'Environmental pragmatism as philosophy or metaphilosophy? On the Weston-Katz debate', in A. Light \& E. Katz (eds.), Environmental pragmatism, pp. 325-338, Routledge Press, New York.

Mill, J.S, 1861, Considerations on representative government, University of Toronto Press, Toronto.

Naess, A., 1984, 'A defence of the deep ecology movement', Environmental Ethics 6(3), 265-270. http://dx.doi.org/10.5840/enviroethics19846330

Norton, B.G., 2003, 'Integration or reduction: Two approaches to environmental values', in D. VanDeVeer \& C. Pierce (eds.), The environmental ethics and policy book: Philosophy, ecology, economics, pp. 240-259, Wadsworth, Belmont, CA.

Norton, B.G., 2005, Sustainability: A philosophy of adaptive cosystem management, The University of Chicago Press, Chicago, IL.

Parker, K.A., 1996, 'Pragmatism and environmental thought', in A. Light \& E. Katz (eds.), Environmental pragmatism, pp. 21-37, Routledge Press, New York.

Pearce, J.A., 2009, 'Concerning all creatures: Reverence for life within a process worldview and the best friends animal sanctuary as an exemplary model', MA dissertation, Graduate Faculty, University of Georgia.

Regan, T., 1983, The case for animal rights, updated with a new preface, University of California Press, Berkeley.

Regan, T., 2004, Empty cages: Facing the challenge of animal rights, Rowman \& Littlefield, Lanham.

Routley, G., 1973, 'Is There a Need for a New, an Environmental, Ethic?,' Proceedings of the XVth World Congress of Philosophy, Sofia Press, Varna, Bulgaria, 17-22 September, pp. 205-210.

Sagoff, M., 2003, 'Taking, just compensation, and the environment', in D. VanDeVeer \& C. Pierce (eds.), The environmental ethics and policy book: Philosophy, ecology, economics, pp. 378-388, Wadsworth, Belmont, CA.

Seeliger, L., 2009, 'On the value of environmental pragmatism in economic decisionmaking: With special reference to the work of Bryan Norton', PhD thesis, Department of Philosophy University of Stellenbosch, Stellenbosch.

Singer, P., 1975, Animal liberation, Random House, London.

Singer, P., 1995, Animal liberation, Random House, New York.

Stone, C.D., 1972, 'Should trees have standing - Toward legal rights for natural objects', Southern California Law Review 45, 450.

Taylor, P.W., 1981, 'The ethics of respect for nature', Environmental Ethics 3(3), 197-218. http://dx.doi.org/10.5840/enviroethics19813321

VanDeVeer, D. \& Pierce, C. (eds.), 2003, The environmental ethics and policy book: Philosophy, ecology, economics, Wadsworth, Belmont, CA.

Weston, A., 1985, 'Beyond intrinsic value', Environmental Ethics 7(4), 321-339. http:// dx.doi.org/10.5840/enviroethics 19857431

Weston A., 1996, 'Beyond intrinsic value', in A. Light \& E. Katz (eds.), Environmental pragmatism, pp. 285-306, Routledge Press, New York.

Woermann, M., 2010, 'A complex ethics: Critical complexity, deconstruction, and implications for business ethics', PhD thesis, Department of Philosophy, Stellenbosch University, Stellenbosch.

Zimmerman, M.E., 2005, The encyclopedia of religion and nature, Continuum, London. 